\title{
REGULATION OF PRESCRIPTION DRUG ADVERTISING: MEDICAL PROGRESS AND PRIVATE ENTERPRISE
}

\author{
RichaRd B. RugE*
}

Communication of new developments in medicine to practicing physicians is an essential step in implementing scientific progress. Each year the pharmaceutical industry spends an estimated $\$ 75^{\circ}$ million in promoting drug products. ${ }^{1}$ As a result of this barrage of advertising, amounting to $\$ 3000$ for every doctor in the United States, a new drug may be widely prescribed within weeks after it has been placed on the market. Recently, the Food and Drug Administration (FDA) has increasingly questioned whether the advertising techniques of drug firms contribute to sound medical progress by helping doctors make informed choices among competing products or instead succeed in selling drugs by misleading claims, omission of crucial data, and inappropriate emotional appeals.

This article examines recent conflicts between the FDA and the drug industry over the purpose of prescription drug "advertising," as that term is peculiarly defined under the Food and Drug Act. ${ }^{2}$ To the FDA, advertisements in medical journals should constitute "post-graduate education" through which doctors learn both the advantages and drawbacks of new drugs. ${ }^{3}$ To industry, advertisements function only to provoke doctors into investigating new drugs through detailed information available in other manufacturer-supplied literature ("labeling") or from independent sources. ${ }^{4}$ The FDA has warned industry to comply with its regulations or find itself altered "significantly, . . . beyond your present fears, and . . . beyond recall." Replying that the FDA exploits the consumer "as a device, or a pretext, for adding further to government power at the expense of the strength and independence of private enterprise," the pharmaceutical industry in 1963 brought the first law suit challenging FDA rules since passage of the basic act in $193^{8 .}{ }^{7}$

* A.B. 1963 , LL.B. 1966, Harvard University. Associate, Hogan \& Hartson, Attorneys, Washington, D.C. Member of the District of Columbia bar.

${ }^{1}$ May, Selling Drugs by "Edtucating" Physicians, 36 J. Medical Ed. 1, 5, 7 (196r). See generally S. REP. No. 448, 87th Cong., Ist Sess. 156-64 (1961) [hereinafter cited as S. REP. No. 448].

${ }^{2}$ Federal Food, Drug, and Cosmetic Act, 52 Stat. 1040 (1938), as amended, 2 I U.S.C. \$\$30I-392 ( 1964 , Supp. II, I965-66).

${ }^{3}$ Address by FDA Commissioner James L. Goddard, Advertising and Government Relations Conference, Washington, D.C., Feb. 8, 1967, in F.D. Cosm. L. Rep., para. 80,16r (1967).

'Jurow, Safe and Effective Prescription-Drug Advertising, 22 Food Drug Cosm. L.J. 57, 63 (x967).

- Address by FDA Commissioner Goddard, meeting of the Pharmaceutical Manufacturcrs Association, Boca Raton, Fla., April 6, 1966, reported in N.Y. Times, April 7, 1966, at 24, col. 4.

- Address by PMA President C. Joseph Stetler, N.Y.C. Pharmaceutical Advertising Club, Inc., Seminar, Oct. 20, I966, reported in 28 F.D.C. RePoRTs No. 43, at S-5, S-6 (Oct. 24, 1966).

${ }^{7}$ Abbott Laboratories v. Celebrezze, 228 F. Supp. 855 (D. Del. I964), rev'd, 352 F.2d 286 (3d Cir. 1965), rev'd and remanded, $3^{87}$ U.S. $136(1967)$. This case is discussed in the text accompanying notes 38-47 infra. 


\section{Background of the Kefauver AMendments}

Prior to the enactment in 1962 of the so-called Kefauver amendments ${ }^{8}$ to the I938 act, the jurisdiction of the Food and Drug Administration reached prescription drug "labeling" but not its "advertising." The statute both before and after the amendments defined labeling to include all "labels," plus other written material on a drug's immediate container or "accompanying such article." Before I962, the FDA gave labeling a broad construction (by expanding the term accompanying) to bring much of the informational type of drug promotion under its control. Thus the agency regulated direct mail advertising to doctors as well as material left in the office by detail men, drug industry salesmen. At the same time, the definition of advertising contracted to cover only newspaper and journal advertisements. This segment of drug promotion fell under the jurisdiction of the Federal Trade Commission (FTC).$^{10}$

However narrow its definition, advertising was extensive in quantity and played an important role in selling drugs. In $195^{8}$, for example, the drug industry paid for 3,790,908,000 pages of advertising in medical journals. The American Medical Association (AMA), the largest publisher of prescription drug ads in the world, grossed \$ro.I million in 1963 from ads in its twelve scientific journals and its laymen's monthly. This large volume of material plus the insistent intrusion of detail men have prompted doctors' complaints about the burden imposed on their time. ${ }^{11}$

Despite these facts, the FTC prior to $\mathrm{x} 962$ possessed little power over drug ads. Advertisements directed solely at physicians-so long as they listed quantitative ingredient information and contained no false representation of a material factwere specifically excluded from FTC control, on the theory that doctors have an expertise enabling them to evaluate drug claims. This rationale probably made sense prior to the prescription drug "revolution" which occurred at the end of the Second World War. Until then the number of drugs available had been relatively limited, and a doctor could fend for himself in selecting medicines; he needed little protection from the law or from regulatory agencies.

But today some eighty new drugs are cleared each year by the FDA; ${ }^{12}$ and ninety per cent of all prescriptions call for drugs manufactured within the past fifteen years. $^{13}$ One economist attributes this extensive introduction of new drugs-or at

${ }^{8}$ Pub. L. No. $87-781,76$ Stat. 780 (1962).

${ }^{\circ} 2$ I U.S.C. $\$ 321(\mathrm{~m})$, (k) (xg64).

${ }^{10}$ Federal Trade Commission Act, I5 U.S.C. $\$ \$ 52-57$ (I964).

${ }^{11}$ See N.Y. Times, June 13, I966, at 26, col. 1.

${ }^{13}$ Hearings on Competitive Problems in the Drug Industry Before the Monopoly Subcomm. of the Senate Select Comm. on Small Business, goth Cong., Ist Sess. 4 (1967) (statement by James L. Goddard, Commissioner of Food and Drugs).

${ }^{13}$ Hearings on Drug Safety Before the Subcomm. on Intergovernmental Relations of the House Comm. on Governmental Operations, 88th Cong., 2d Sess. 14 (1964) (statement by George P. Larrick, Commissioner of Food and Drugs). 
least of new combinations and dosage forms of old drugs-to industry's efforts to replace price competition among relatively standardized drugs with product differentiation or competition "in innovation."14 As a part of these efforts, companies make heavy advertising outlays to maintain their existing market share through constant introduction of "new" drugs. A new product will reach its peak in the second year following its introduction, then decline "rapidly in relative importance."15

More important, today advertising not only sells new drugs but also tells the physician about their existence and their claimed effectiveness for the first time. An AMA study ${ }^{16}$ for example, disclosed that medical journal ads constitute one of the largest sources of information to practitioners about newly discovered drugs. Forced to "contend with subtle overpowering promotion and the complexities of modern medicine," today's doctor cannot effectively fend for himself, "especially if he is to be 'educated' by the very purveyors of products which require his prescriptions."17

Prior to 1962 responsible doctors began to question the propriety of educating physicians through unpoliced ads. Pointing out that many doctors assume that at least some reputable firms consistently disseminate reliable information, Dr. Charles D. May wrote: ${ }^{18}$

The traditional independence of physicians and the welfare of the public are being threatened by the new vogue among drug manufacturers to promote their products by assuming an aggressive role in the "education" of doctors. ... Is the public likely to benefit if practicing physicians and medical educators must perform their duties amidst the clamor and striving of merchants seeking to increase the sales of drugs by conscripting "education" in the service of promotion? Is it prudent for physicians to become greatly dependent upon pharmaceutical manufacturers for support of scientific journals and medical societies, for entertainment, and now also for a large part of their education?

Another distinguished doctor has more recently charged that "persuasive propaganda of advertising literature and of visiting detail men" causes physicians to shift "repeatedly and needlessly from one drug to another."10

[Doctors] are being systematically brainwashed by expensive advertising in the pages of medical journals, by the daily influx of mountains of advertising mail, by free throw-away "educational" pamphets published by commercial agencies for the promotion of drug sales, and by visiting detail men, who go from door to

\footnotetext{
${ }^{14}$ Comanor, Research and Competitive Product Differentiation in the Pharmaceutical Industry in the United States, 31 Economica 372-73, 375 (1964). See Steele, Monopoly and Competition in the Ethical Drugs Market, 5 J. Law \& Econ. 131, I4I (1962). See generally J. BackMan, Advertising and ComPETITION $(\mathrm{rg} 67)$.

${ }^{15}$ Comanor, supra note 14 , at 376.

${ }^{16}$ Attitudes of U.S. Physicians Toward the American Pharmaceutical Industry, Study conducted by Ben Gaffin and Associates, Inc., Chicago, Ill., in 1959 for the AMA, cited in S. Rep. No. 448, at 190. See also Demeritt, Effectiveness of Pharmaceutical Promotion to Hospital Pharmacists, 23 AM. J. Hosp. Pharmacy 13, I6-I7 (1966).

${ }^{17}$ May, supra note $x$, at 8-9.

${ }^{28}$ Id. at I.

${ }^{19}$ Baehr, Drig Costs and the Constmer, in Drucs IN OuR Soctery 179, I82 (P. Talalay ed. 1964).
} 
door of physicians' offices leaving elaborate samples of new drugs and valueless combinations of old drugs, together with reams of impressive but biased literature. It is utterly impossible for most busy physicians to separate the wheat from the chaff in this enormous volume of information and misinformation. ${ }^{20}$

Hearings held by Senator Estes Kefauver before the Senate Subcommittee on Antitrust and Monopoly in 196I and 1962 focused attention on such abuses. Out of these hearings, with the help of public concern aroused by the thalidomide tragedy, there developed the Drug Amendments of 1962.

The amended law placed on the pharmaceutical industry a greater responsibility to present factual and undistorted information to doctors than did the 1938 act, and gave jurisdiction to regulate prescription drug advertising to the Food and Drug Administration, ${ }^{21}$ leaving control over nonprescription drug advertising to the FTC. Although FDA regulations issued under the 1962 amendments have imposed similar requirements for both advertising and labeling, the distinction between the two kinds of printed literature remains important-for example, side effects must be fully stated in labeling but may be summarized in advertising. ${ }^{22}$

The amended statute does not specifically give the FDA authority over oral promotional statements made by detail men. These salesmen are also an important source of information about new drugs, making an estimated $\mathrm{I} 8$ to 20 million calls a year on doctors and druggists. ${ }^{23}$ The original version of the 1962 amendments included oral claims as advertising; this provision, ${ }^{24}$ not enacted, would have required detailers to supply the generic name and warnings for drugs. Absent such a rule, promotional statements by detailers cannot be easily categorized as either labeling or advertising. The FDA does, however, have jurisdiction over literature left by detailers with doctors. The judiciary may fill this legislative gap. A recent case held a manufacturer liable where the company had warned doctors of a newly discovered side effect by product cards and letters but its detailers had remained silent. ${ }^{25}$

President Johnson has proposed legislation to control the unsolicited distribution of samples, ${ }^{26}$ another major form of drug promotion costing \$roo million per year. ${ }^{27}$ The proposed Drug Safety Act of 1967 would not restrict person-to-person distribution from detailer to physician but would forbid drug companies to send samples through the mails except to a doctor requesting samples of a particular drug in writing.

Regulations covering prescription drug advertising can be divided into three

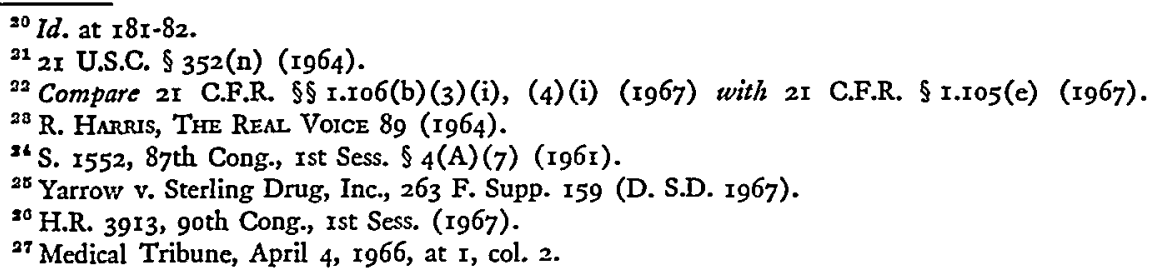


general areas. First, the FDA has issued controversial rules controlling drug names; related to these requirements are FDA rules compelling disclosure of certain essential ingredient information. Second, additional information needed before prescribing a drug - its side effects and contraindications-must also be listed. Finally, the FDA has recently moved to regulate the content of drug advertisements to ensure that the limits of the drug's effectiveness are accurately portrayed. These subjects are taken up below.

\section{II}

\section{Regulation of Drug Names}

A discrete drug substance may be known by three types of names. Its chemical name simply lists every part of a drug's molecular structure. Its generic name abbreviates the components but still informs a doctor of the drug's chemical composition, from which he can determine its general effect on the body. Ordinarily a drug will have only one generic or nonproprietary name. Finally, a drug is sold under a trade or brand name which identifies the drug with a particular manufacturer but conveys little information about its nature or composition. Several manufacturers often market the same chemical substance under different trade names.

Senator Kefauver felt that the purpose of the vast sums spent by the drug industry on promotion was to persuade doctors to prescribe by trade name rather than by generic name. ${ }^{28}$ Since the same product sold by trade name may cost several times as much as when sold by generic name, ${ }^{29}$ advertising which planted the brand name firmly in the prescribing doctor's mind left the ultimate consumers "captives of the drug industry."30 This promotional effort largely succeeded; 91.9 per cent of 1964 prescriptions called for trade name drugs. ${ }^{31}$

Although Congress rejected Senator Kefauver's chief proposal for encouraging prescription by generic name (government licensing of drug manufacturers), ${ }^{32}$ the 1962 amendments require that a drug's "established name" must appear on each piece of promotional material in "direct" conjunction with its trade name..$^{33}$ To alert doctors to the exact relationship between the two designations, the established name must be surrounded by brackets or preceded by a phrase such as "brand of." The established name must be "printed prominently and in type at least half as large as

\footnotetext{
${ }^{28}$ S. Rep. No. 448 , at 105, 23I-44; 107 Cong. Rec. 5638 (1961) (remarks of Senator Kefauver).

${ }^{29}$ S. Rep. No. 448, at 105, 23I-44. See generally R. Burack, The Handbook op Prescription Drugs (1967). However, a survey conducted for the AMA of noo Chicago drug retailers concluded that generic name prescribing did not necessarily cut drug costs. N.Y. Times, June 9, 1967, at 26, col. 3 .

${ }^{80}{ }_{107}$ CoNG. REc. 5638 ( $x 96 \mathrm{r}$ ) (remarks of Senator Kefauver).

${ }^{31}$ N.Y. Times, June 13 , Ig66, at 27, col. I. Additional factors may explain this fact. The generic name is often omitted in drug advertising and labeling; the trade name may be easier to pronounce, spell, and therefore remember; and it has been suggested by industry detail men that drugs produced and sold by smaller companies are of substandard quality. S. REP. No. 448, at 231-34.

${ }^{32}$ S. 1552, 87 th Cong., Ist Sess. $\S \S 4(\mathrm{~A})(7),(13)$ (196r).

${ }^{33} 2$ I U.S.C. $\$ \$ 352(e)$, (n) $(1964)$.
} 
that used for any trade or brand name." ${ }^{34}$ In addition, the amendments seek to assure doctors of drug quality by certain safeguards over manufacturing, including registration and inspection..$^{35}$

Early in 1963 the Food and Drug Administration issued regulations requiring that the established name of a prescription medicine accompany every appearance of the drug's trade name on all labels, labeling, and advertising, no matter how many times the brand name may be repeated on any single page. ${ }^{36}$ The FDA contended that the "every-time" regulations were crucial to the 1962 amendment in light of the "evident intent" of Congress to popularize established names. ${ }^{37}$ Arguing that the statute dictates only the manner in which the generic name must appear, and not its frequency, the Pharmaceutical Manufacturers Asssociation and thirty-seven of its members sought a declaratory judgment in the U.S. District Court for Delaware, invalidating the regulations as exceeding the FDA's statutory authority ${ }^{38}$

This suit in $1963^{39}$ was the first legal challenge to FDA regulations since passage of the basic act in 1938. The drug industry's concern extended beyond the estimated million-dollar cost of reprinting its existing labels to comply with the every-time requirement. ${ }^{40}$ The regulations struck at the purpose of drug promotion, the implantation of trade names in the doctor's mind; they sought to lower drug prices by educating physicians to prescribe by generic names. But increased familiarity with nonproprietary names, the industry feared, would endanger its investment in brand names and in research for new and better products, little of which is undertaken by smaller, generic-name producers.

It was claimed that conspicuous disclosure of the generic name, to which the industry did not object, would notify the physician of the drug's active ingredients. He could then choose among the various sources producing the same or comparable chemical substances at different prices. Constant repetition of the established name, on the other hand, might make advertising and labeling less readable. (In fact, compliance with the every-time rule does not substantially affect over-all appearance. $\left.{ }^{41}\right)$ Finally, the industry complained that the regulations would induce doctors to believe that drugs "with the same established name are always and in all respects

\footnotetext{
${ }^{81} 2$ I C.F.R. $\$ \S I .104(\mathrm{~g})$, I.IO5(b) (1967). The regulations prescribe that "[T]he established name shall have a prominence commensurate with the prominence with which such proprietary name or designation appears, taking into account all pertinent factors, including typography, layout, contrast, and other printing features." 2I C.F.R. $\$$ I.105(b)(2) (I967).

${ }^{36}{ }_{21}$ U.S.C. $\S \S 33 I(\mathrm{p}), 35 \mathrm{I}(\mathrm{a}), 352(\mathrm{o}), 374$ (I964); $\$ 360$ (I964, Supp. II, I965-66).

${ }^{\text {so }}$ 2I C.F.R. $\$$ r.104(g)(I), I.I05(b)(I) (I967).

${ }^{37}$ F.D. Cosm. L. REP., para. 40,060 (1963).

${ }^{88}$ Complaint, Abbott Laboratories v. Celebrezze, Civil No. 2737 (D. Del. 1963), reported in F.D. CosM. L. REP., para. 40,060 (1963).

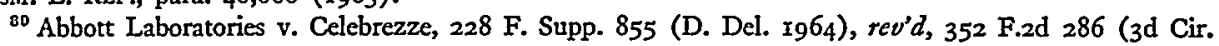
1965), rev'd and remanded sub nom., Abbott Laboratories v. Gardner, 387 U.S. I36 (I967).

${ }^{10}$ N.Y. Times, Sept. 6, 1963, at 1 , col. 5 .

${ }^{4}$ See, e.g., Advertisement for Polycillin (ampicillin trihydrate), J.A.M.A. July 3x, I967, at I-3.
} 
identical," when in fact drugs with the same generic name but different proprietary names "can and do differ in their therapeutic effect."

The district court invalidated the regulations as contrary to the intent of the 1962 amendments. ${ }^{43}$ The Third Circuit reversed on procedural grounds, holding that there was no actual case or controversy as required for justiciability under the Declaratory Judgment Act $^{44}$ because no real threat of immediate prosecution had been presented..$^{45}$ On May 22, rg67, the Supreme Court reversed this decision, finding that "the impact of the regulations ... is sufficiently direct and immediate so as to render the issue appropriate for judicial review at this stage, ${ }^{346}$ and remanded the case to the court of appeals for decision on the substantive issues.

On October 20, I967, the day set for further argument in the Third Circuit, the FDA and PMA announced settlement of the litigation. ${ }^{47}$ The FDA will replace the contested every-time rules with new regulations. On any page of advertising or labeling which "features" a drug's trade name, the generic name must appear "in direct conjunction with" and in type one-half as large as the brand name each time the latter is featured, but need not appear again in promotional copy on the same page. If a trade name is used but not "featured," the generic name must appear at least once with the most prominent display of the trade name. In addition, each column of text providing detailed information on effectiveness or side effects must include the generic name at least once "in association with" the trade name, if used, in the same size type as that used for the text. If the trade name appears in type size larger than that used for the column text, the generic name must again be half as large as the trade name.

In light of publicity recently given to generic-name prescribing in recent congressional hearings, ${ }^{48}$ however, the FDA need not insist vigorously on "educating" doctors to use generic name drugs, so long as the generic name is "prominently" disclosed in drug advertising. A survey of ads in recent journals shows that, contrary to FDA regulations, the generic name type face does not always appear half as bold or wide as that used for the trade name; in many cases, the generic name is not preceded by a phrase such as "brand of" nor surrounded by brackets or parentheses.

\footnotetext{
$\$ 2$ For the industry's position, see the complaint and plaintiff's briefs filed in $228 \mathrm{~F}$. Supp. 855 . Recently, the FDA ordered generic manufacturers to stop marketing their versions of the antibiotic chloramphenicol, sold as Chloromycetin by Parke, Davis, \& Co. Parke-Davis had submitted test data to the FDA indicating that its version entered the blood stream quicker than the others. Some medical experts attribute this advantage to the different shapes of chloramphenicol crystals used in the trade-name drug. Wall Street Journal, Jan. 22, 1968 , at 6 , col. $2 ; i d$., Dec. 26,1967 , at 4 , col. 3 . The FDA has not, however, announced any rule requiring generic manufacturers to show that their products work as cffectively in patients as the chemically equivalent brand-name products.

13228 F. Supp. at 864 .

428 U.S.C. $\$ 2201$ (1964).

${ }^{15} 352$ F.2d at 29 r.

${ }^{18} 387$ U.S. at 152 .

17 See Food and Drug Reg., 2I C.F.R. $\$$ r.105, 33 Fed. Reg. 3217-r 8 (Feb. 21, 1968).

${ }^{48}$ Hearings on Competitive Problems in the Drug Industry Before the Monopoly Subcomm. of the Senate Select Comm. on Small Business, goth Cong., Ist Sess. (1967).
} 
The new rules, of course, may lead to new controversies over their exact interpretation, but they appear to be a reasonable compromise. Commentators have split on the question whether the now-withdrawn every-time regulations were consonant with congressional purpose. ${ }^{40}$ Ambiguity in the statutory provision on generic names and in its legislative history probably indicate that Congress had no "intent" on the question of frequency. The AMA, which generally supports the industry against the FDA, urges doctors to prescribe by trade name..$^{50}$

\section{III}

\section{Disclosure of SIDE EFFECTS}

More than one million adverse reactions to drugs occur annually in the United States. These unwanted effects often occur even when a drug is administered according to the manufacturer's directions. Information on a drug's recurrent side effects, or rarer but serious adverse reactions, is obviously important to a doctor weighing alternative medications, especially since many side effects are not allergic or unusual genetic reactions peculiar to the patient but pharmacological effects of the drugs. ${ }^{\text {51 }}$ Similarly, the doctor must know what pathological conditions contraindicate use of the drug. The Kefauver hearings found, however, that drug manufacturers sometimes failed to disclose to doctors or to the FDA reports in their possession of serious and even fatal side effects. ${ }^{52}$

In particular, the hearing revealed that prescription drug advertisements failed to list or discuss possible adverse reactions. A survey of promotion in six leading medical journals, ${ }^{53}$ covering thirty-four important trade name drugs advertised in a total of 2033 pages during a nine-month period ending in March 1959, found that in eighty-nine per cent of the ads there was "no reference to side effects at all or only a short dismissal phrase which was typically less a warning than a reason for prescribing." Among the advertisements surveyed were several for Diabinese (chlorpropamide), an oral antidiabetic introduced in $x 958$ by Chas. Pfizer \& Co., Inc. Although its promotion claimed an "almost complete absence of unfavorable side effects," a report prepared for Pfizer showed twenty-seven per cent incidence of side effects, including jaundice. ${ }^{54}$ Doctors polled by an AMA study on misleading advertising termed such failure to cite side effects "the most heinous crime a pharmaceutical company can commit."55

\footnotetext{
${ }^{40}$ Compare Note, Drug Amendments of 1962-Generic Name Prescribing: Drug Price Panacea?, 16 Stan. L. Rev. 649 (1964) with Note, The Drug Amendments of 1962: How Much Regulation?, I8 Rutgers L. Rev. Ior, I27-30 (I963) and Sweeney, The "Generic Every Time" Case: Prescription Drug Industry in Extremis, 21 Food DRug Cosm. L.J. 226 (I966).

${ }^{50}$ Editorial, Drug Names, rgo J.A.M.A. 542 (1964).

${ }^{2}$ N.Y. Times, May 5, 1965, at 63 , col. I (study at Johns Hopkins University).

${ }^{2}$ M. Mintz, The Therapeutic Nighmare 13-32 (1965).

ss. REP. No. 448 , at I99. The journals surveyed included 7AMA, the New England Journal of Medicine, and Medical Economics.

"Id. at $211,218$.

${ }^{\varpi 5}$ See 108 CoNG. REc. 21,086 (I962) (remarks of Representative Dingeli).
} 
Drug industry spokesmen counter that physicians can obtain full side-effect information elsewhere, particularly on the package insert which must accompany each prescription drug and sample and on all promotional labeling. ${ }^{50}$ They contend that advertisements, aimed solely at doctors, serve only as "product reminders" and thus should not be treated as labeling. However, this argument begs the question of the importance of journal advertising in presenting drug news and overstates the adequacy of alternative sources of information on side effects. First, doctors often ignore the vast quantities of promotional labeling sent to their offices; they are most apt to study ads appearing next to scientific articles in prestigious medical publications such as the Journal of the American Medical Association (JAMA) and the New England Journal of Medicine. ${ }^{57}$ Second, the package insert goes not to the doctor who needs the "full disclosure" labeling but to pharmacists.

The better journals do carry reports critical of new drugs. In early Ig60, for example, JAMA noted thirty-five cases of baby girls with male characteristics born to women who had been given Norlutin (norethindrone), a hormone used in gynecologic disorders, during pregnancy. ${ }^{68}$ But ads for Norlutin in $J A M A$ during the following three months did not cite this side effect. Despite the fact that warnings given only in journal articles (which generally would appear but once) may be ineffective to deter improper use of a drug, JAMA did not request the advertiser to add a warning. ${ }^{59}$

Moreover, the responsible medical publications may not review all the new drug products unleashed yearly. Another potential source of information, Physicians' Desk Reference, a commercially produced manual of therapeutic agents distributed free to doctors, carries warnings supplied by manufacturers. The FDA has filed criminal informations against two drug compaines for allegedly failing to make full side-effect disclosures in $P D R$, which the agency considers labeling; Pfizer Laboratories recently notified doctors that the FDA considered its 1967 PDR entries for two drugs inadequate. ${ }^{80}$ The sharpest critic of new drugs is the Medical Letter, which carries no advertising. Its effectiveness is limited, however, because fewer than 35,000 doctors subscribe.

To meet this need for disclosure, the 1962 amendments require any prescription drug advertisement listing indications or dosage recommendations-that is, any ad except a strictly reminder piece-to contain "a true statement of ... information in brief summary relating to side effects, contraindications, and effectiveness" as called for by regulations. ${ }^{61}$ In what detail must relevant side effects and contraindications

\footnotetext{
${ }^{56}$ N.Y. Times, July 20, I963, at 19 , col. I (criticism of FDA by PMA).

${ }^{67}$ S. REP. No. 448 , at $160-64$.

${ }^{58}$ Wilkins, Masculinization of Female Fetus Due to Use of Orally Given Progestins, I72 J.A.M.A. $1028(1960)$.

${ }^{80} \mathrm{M}$. MiNTZ, supra note 52 , at 84 .

${ }^{60}$ Washington Post, May 24, 1967 , at 2, col. I.

${ }^{61} 2$ I U.S.C. $\$ 352(\mathrm{n})$ (1964); 21 C.F.R. § I.105(e) (1967).
} 
be presented? The answer depends on the size of the advertisement and the quantity of side effects. An ad of three pages or less, condensing information on effectiveness, may "concisely" present each side effect found in the drug's full-disclosure labeling; in an ad of more than three pages presenting extensive claims of effectiveness, the side effect information should similarly expand into a "discussion" of precautions. ${ }^{62}$ But there is not precise matching requirement for stating the two types of information in an equal number of words, an equal amount of space, or in the same type size. Thus, if headlines, advertising leads, and photographs are used to convey information on effectiveness, similar techniques need not be used to communicate side effect information.

While the FDA may consider the size of the ad and the conditions for which the drug is offered in determining whether there has been adequate disclosure, the statute only requires a "brief summary," which Senator Kefauver described as a "fair condensation of the full disclosure information already required in labeling. . .."63 To comply with the advertising regulations, the manufacturer ordinarily summarizes the precaution and side-effect section of the package insert. For example, compare the $x 966$ package insert warning as to renal impairment and the corresponding advertising side-effect information for Declomycin (demethylchlortetracycline $\mathrm{HCl}$ ):

\section{Labeling ${ }^{64}$}

Advertising ${ }^{65}$

If renal impairment exists, even usual Reduce dosage in impaired renal function. oral or parenteral doses may lead to excessive systemic accumulation of the drug and possible liver toxicity. Under such conditions, lower than usual doses are indicated and if therapy is prolonged, ... serum level determinations may be advisable.

To test compliance with its disclosure regulations, the FDA must gather and evaluate reports on adverse reactions, especially those occurring after a new drug is first sold. Until recently, there were no reliable systems for retrieving such information; for example, most hospitals did not encourage members to record recognized drug reactions. Today, side-effect data from numerous sources feeds into the FDA's Information Center on Adverse Reactions and Hazards, where it is studied and catalogued. Some 6600 hospitals supply the FDA with drug information. The agency also collaborates with the AMA central registry of adverse reactions, which receives drug news from hospitals not reporting to the FDA and from doctors in private practice. All federal medical services and agencies send side-effect

\footnotetext{
${ }^{62}$ Food and Drug Reg. $\S$ I.I05(e)(5)(xxix), 32 Fed. Reg. 7535 (May 23, 1967). See letters from George P. Larrick, former FDA Commissioner, to Gerhard A. Gesell, Oct. I, 1963, Oct. 9, I963, reported in F.D. CosM. L. REP., para. 40,063 (r963).

${ }^{63}$ I 08 CoNG. REC. 22,039-40 (remarks of Senator Kefauver).

ot Labeling for Declomycin (demethylchlortetracycline), dated February r965.

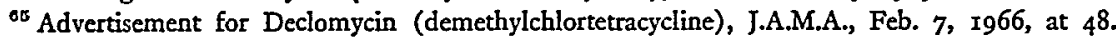


reports to the FDA, and eight countries will exchange information through an international center created by the World Health Organization to provide a worldwide early warning system for drug news. ${ }^{66}$

Under the $\mathrm{x} 962$ amendments the FDA requires manufacturers to record side effects and other clinical data as received and to report information relating to the drug's safety and effectiveness. ${ }^{67}$ The reporting regulations are important because the manufacturer has more knowledge about the marketing experience of his drug than any other source, since he picks up information from doctors and his detail men. $^{68}$ The regulations have already brought to the FDA reports of adverse reactions which would not have been previously available. These are screened by the Information Center on Adverse Reactions and Hazards, which receives 150,000 reports annually and may get significant information on reactions to a new drug within three months after it is first sold. The Center may then recommend precautionary labeling, changes in existing labeling, issuance of a warning letter, or withdrawal of the drug from use.

In turn, the FDA publishes monthly reports on adverse reactions and a weekly journal of literature abstracts, which are sent to cooperating hospitals and other groups. FDA Commissioner James L. Goddard has proposed that a compendium of drug information approved by the FDA be distributed free to doctors; if this were done, the agency would drop its requirements that full-disclosure package inserts accompany the marketed or dispensing package of all prescription drugs. ${ }^{.0}$

In December 1965, the Food and Drug Administration initiated its first prosecution under the advertising provisions of the 1962 amendments. ${ }^{70}$ The FDA charged that ads for Pree MT, marketed by Wallace Laboratories, a division of CarterWallace, Inc. (formerly Carter Products), omitted essential side effect and contraindication information. The United States District Court for New Jersey imposed the maximum $\$ 2,000$ fine after the defendant pleaded no contest.

Pree MT combines meprobamate, a tranquilizer sold separately as Equanil or Miltown, with hydrochlorothiazide, which removes excess fluids from body tissues. An ad appearing in four June 1964 issues of JAMA claimed, "Contraindications: None known," and urged doctors to prescribe the drug for premenstrual tension. The FDA insisted that the ad's brief summary omitted warnings that hydrochlorothiazide is contraindicated in patients who have had suppressed urine flow and that patients given it should be watched for signs of serious and sometimes fatal blood diseases; that Pree MT can precipitate gout, and that its use should be halted in patients with severe kidney disease or liver disease; and that meprobamate may cause skin rash, bronchial spasm, skin hemorrhages, and blood-vessel disturbances.

\footnotetext{
${ }^{66} 52$ Dep't State Bull. 814 (x965).

${ }^{\circ 7}$ See $2 x$ U.S.C. $\$ \S 355$ (i), (j) (I964).

${ }^{08}$ Pisani, Drug Safety and the FDA, 2 I Food Drug Cosm. L.J. 68, 74 (1966).

${ }^{69}$ Washington Evening Star, Aug. II, I967, at C-6, col. 5 .

${ }^{70}$ Washington Post, Dec. 7, 1965, at 12, col. I; id., Jan. 18, 1966, at 4, col. I.
} 
The FDA has also charged that Ciba Pharmaceutical Co. "kept secret" reports showing that Elipten (amino-glutethimide), prescribed for control of epilepsy, caused sexual precocity, masculinization of young females, and other "untoward effects"; 7 that Wyeth Laboratories and Merck \& Co. delayed in reporting adverse effects on the eyes of dogs caused by the controversial experimental drug DMSO (dimethyl sulfoxide) $;^{72}$ and that Merck, Sharp, \& Dohme failed to report immediately (as required) "alarming" findings of breast cancer in four of six dogs given an experimental birth control pill, MK-665, combining mestranol and ethynerone. ${ }^{73}$

\section{IV}

\section{Regulation of Advertising Content}

The drug industry contends that once the FDA assures adequate disclosure of effectiveness, side-effect, and contraindication information within the "brief summary" portion of an advertisement, the agency has no further jurisdiction to regulate the content of the ad or the promotional techniques used. ${ }^{74}$ The FDA asserts that Congress intended the 1962 amendments to grant power "to deal completely, and not partially, with the problems of false and misleading advertising which had been called to its attention" during the Kefauver hearings. ${ }^{75}$ Thus, it is argued that Congress introduced the phrase "brief summary" only to authorize "a stripped-down statement of the drug's effectiveness, side effects, and contraindications when the sponsor wished to limit the size of his ad"; and so the agency retains jurisdiction over the entire advertisement. Exercising this power, the FDA has issued regulations which utilize the "brief summary" provision as a counterbalance to overpromotion.

Hearings conducted by Senator Kefauver repeatedly aired criticism by physicians of the promotional tactics used in drug advertising. ${ }^{76}$ The problem of selling doctors on new drug products each year, of which as few as thirteen may be new single chemical entities, ${ }^{7 \tau}$ has led to "clamorous competitive claims" presented in a style designed "to achieve uncritical acceptance of a preconceived message-to captivate the mind."78 For example, Dr. Charles D. May of Columbia University has charged that from $195^{8}$ to I96I drug firms launched an "exuberant" and "hectic" campaign to increase sales of antibiotics; the "confused and misleading barrage of promotion" presented "inadequate and irrelevant data" in a "triumphant tone." "The "educational' effect on doctors was to confuse them and lead them to believe wonderful

${ }^{72}$ Washington Post, Feb. 16, 1966, at 8, col. 3 .

73 Washington Post, March 10, I966, at $\mathrm{x}$, col. 5 .

${ }^{73}$ Washington Post, March II, x966, at I, col. 3 .

74 See Pharmaceutical Manufacturers Association, Comments on Proposed Prescription Drug Advertising

Regulations, 32 Fed. Reg. 7533-37 (May 23, 1967), filed with the FDA on August 29, 1967.

${ }^{75}$ Letter of Oct. I, I963, stupra note 62.

${ }^{70} \mathrm{~S}$. REP. No. 448 , at $164-90$.

${ }^{77}$ N.Y. Times, June $4,1967, \S 3$, at $I$, col. 2 .

${ }^{78}$ May, supra note $\mathrm{I}$, at ro. 
new drugs were available" when in fact what development there had been was altogether minor. ${ }^{79}$

Need for government regulation in this area exists partly because leading medical publications have not strictly supervised the drug advertising which they publish. From $x 953$ through I960 the AMA, which reaches over 200,000 subscribers through $J A M A$, gradually relinquished its earlier policing powers over advertisements. ${ }^{80}$ Although the AMA today asserts that ads in $I A M A$ "have been reviewed to comply with the principles governing scientific advertising in AMA scientific publications," it responded to the Pree MT prosecution by stating that censorship of advertisements is "fundamentally a matter for manufacturers." 81

A drug advertising writer, in turn, places responsibility for misleading overpromotion on the doctor. Pointing out that few physicians subscribe to the Medical Letter, an independent newsletter attacked by industry "for presuming to pass on advertising claims, the validity of supporting evidence, and the inherent merit of drugs," the late Pierre R. Garai asked: ${ }^{22}$ "In light of this kind of response, is it any wonder that drug advertisers should be unimpressed by the professional maturity of the bulk of their audience or that campaigns for ethical drugs should sometimes seek to manipulate physicians rather than communicate with them?" To avoid becoming "a sitting duck for color spreads," the doctor should develop a healthy skepticism concerning ads: "He must cultivate a flair for spotting the logical loophole, the invalid clinical trial, the unreliable or meaningless testimonial, the unneeded improvement and the unlikely claim. Above all, he must develop greater resistance to the lure of the fashionable and the new." ${ }^{\prime 83}$ The industry would presumably react to critical appraisal of its ads by supplying more reliable information.

Aside from the dubiousness of his proposition that responsibility for providing accurate advertising lies with the reader, Garai's argument can be criticized on two grounds. Doctors do not have time to check claims by ferreting out more authentic analyses elsewhere. And the evidence cited in the ads themselves as backing up claims made may consist of unpublished data ("personal communications"), case reports in the company's files, exhibits at meetings, testimonials from anonymous sources, and citations from inaccessible or inferior journals. ${ }^{84}$

To fill this gap in control over drug ad content, the FDA issued in 1963 two important regulations. The first required a "fair balance . . . in presenting the information on effectiveness and that on side effects and contraindications." second, which the FDA considered part of the "fair balance" requirement, stated

\footnotetext{
${ }^{70}$ Id. at 3 .

${ }^{80}$ R. Harris, The Real Votce 126 (1964).

${ }^{81}$ Washington Post, Dec. 7, 1965, at I2, col. x.

${ }^{82}$ Garai, Advertising and Promotion of Drugs, in Drugs in Oun Socrety 189, I96 (P. Talalay ed.

${ }^{83}$ Id. at 199.

${ }^{84}$ May, supra note $I$, at II.

${ }^{85} 21$ C.F.R. § 1.105(e) (1967).
} I964). 
that information concerning side effects and contraindications "shall appear in reasonably close association with the information concerning effectiveness and shall have the same relative degree of prominence as the information concerning effectiveness, taking into account all pertinent factors, including typography, layout, contrast, and other printing features." ${ }^{86}$

The FDA interpreted these regulations to require at least that information on side effects given as part of the brief summary be readable, that is, that disclosure of precautions must be effective as well as adequate. Thus the type size used should compare reasonably with that describing the drug's benefits and in no case be unduly compressed. $^{87}$ Headings such as "Side Effects," "Contraindications," and "Precautions"-and not meaningless terms such as "In Summary" or "Special Considerations"-must introduce and plainly identify the warning data.

In addition to ensuring the readability of the cautionary portion of advertisements, the FDA required that ads be arrangèd so that "this important information will be read." Photographs, headlines, and type size must not overwhelm "essential side effect and contraindication information ... [or] minimize its disclosure as part of the total message the advertisement conveys." For example, although the fair balance regulation does not require an ad containing a picture relating to a drug's effectiveness also to contain a picture relating to side effects, the former should not overplay the effectiveness, nor suggest use of a drug when contraindicated, nor create an impression that minimizes pertinent side effects. Similarly, information on indications already presented by graphic means, headlines, or discussion in the body of the ad should not be unnecessarily repeated in the brief summary portion so as to divert doctors from reading the side-effect information. Visual appeal of the summary report, as compared with the information on effectiveness, must be sufficient to make it a "conspicuous and easily perceived part of the total advertisement."

The FDA rules rest on the concept that precautionary information about drugs "should be presented as a part of the central message of the advertisement" to give a fair and balanced picture of the "good and the bad" of the drug. ${ }^{88}$ The brief summary thus plays a more important role than that of merely supplying a list of warnings for the conscientious doctor to read. Even if the side-effect information may be obtained elsewhere, and even if the doctor does not scrutinize the summary, its prominence reminds him that there are limits to the drug's effectiveness. And it provides a measuring rod against which the more extravagant claims in the ad may be tested.

\footnotetext{
${ }^{80} 21$ C.F.R. $\$ 1.105(i)(1967)$. These regulations have been carried forward, in modified language, in the new FDA advertising rules.

${ }^{87}$ Statements in this and following paragraphs based on Letters, supra note 62.

${ }^{88}$ Letter of Oct. 9, 1963 , supra note 62; Yakowitz, Drug Labeling and Promotion (Comments), 20 Food Drug Cosm. L.J. 97 (1965).
} 
New regulation $\mathrm{s}^{89}$ issued by the FDA on May 17,1967 , to which industry has entered strong opposition, spell out that the FDA sees a third kind of fair balance required for prescription drug advertising beyond that $(\mathrm{I})$ within the brief summary portion of the ad and (2) between the brief summary portion and the promotional copy-namely, (3) within the promotional copy itself. Thus the new regulations, as originally worded, order as follows:

Scope of information to be included in brief summary. (i) The advertisement as a whole and each representation and suggestion in the advertisement shall be consistent with the requirement that it present a true statement of information in brief summary relating to side effects, contraindications, and effectiveness whether or not it relies on a distinct part of the advertisement to present information relating to side effects and contraindications.

This means that the ad must display the drug's limitations "in immediate conjunction with and as prominently as any claim for effectiveness," and that specific side effects must appear in "immediate conjunction with" each claim for safety whether or not such limitations and side effects are listed in a separate portion of the advertisement. For ads of over three pages, the side-effect information must appear as a "Brief Discussion Summary" which is "comparable in depth and detail" to that in full-disclosure labeling, even if effectiveness claims are summarized, in addition to appearing in the text next to any safety claims. In final form, the language of the regulations will be modified to assure the industry that each sentence of an ad need not present a complete report on the drug, although the ad as a whole must comply with the FDA's requirements.

Although the FDA has disclaimed any intention of regulating advertising techniques per $s e,{ }^{90}$ the new rules cover comparative claims, traditionally disregarded by the law as mere "puffing" which all but the most gullible consumers ignore. The rules forbid any claim or suggestion-either directly or through cited referencesthat a drug is better, safer, or more effective than its competitors, unless the claim has been approved by the FDA for labeling or has been demonstrated by "substantial evidence." Moreover, any assertion of superiority must be balanced by disclosure of those disadvantages shared with the "inferior" drugs plus those drawbacks unique to the "better" drug.

The agency's concern in this area may have stemmed from advertising for two oral contraceptives. The FDA charged ${ }^{91}$ that Mead Johnson's description of Oracon (ethinyl estradiol, dimethisterone) as safer than and superior to other birth control pills was deceptive because there is no substantial evidence that one oral contraceptive

\footnotetext{
${ }^{80}$ The regulations referred to in this and succeeding paragraphs may be found at 32 Fcd. Reg. 7533-37 (May 23, 1967 ).

${ }^{00}$ Goodrich, Responsibilities and Problems of Government, in DRUGS IN OUR Societr 141, 146 (P. Talalay ed. 1964).

${ }^{9 x}$ Address by FDA General Counsel William W. Goodrich, N.Y.C. Pharmaceutical Advertising Club Seminar, Oct. 20, rg66, reported in 28 F.D.C. Reports No. 43, at S-ro, S-II (Oct. 24, 1966).
} 
outperforms the others, and that Eli Lilly wrongly claimed that women using its C-Quens (mestranol, chlormadione acetate) will gain less weight than those using nonsequential pills. The agency then required that labeling for all oral contraceptive brands display exactly the same prescribing warnings, thereby effecting some equalization of sales appeal. ${ }^{92}$ Because six million American women are using these pills, and because their safety has not yet been conclusively shown, such stringent actions may be justified.

Exaggerated claims of superiority may achieve credibility when backed by an impressive-looking block of citations. Many of the thirty-four specific practices condemned in the new regulations pertain to the use of quotations and references in ads. A kind of "fair balance" is required here also; thus an ad is misleading if it

-ignores recent literature references for more favorable obsolete data;

-ignores published articles detailing side effects for literature reporting none; -implies that a study reflects greater experience with the drug than it does in fact; -fails to reveal that favorable studies conflict with other reliable studies; or -improperly suggests that animal studies have clinical significance.

Even when accurately reported, studies cited in ads must have independent validity. Drug firms may not cite a study "that lacks significance because it was uncontrolled or for other reasons;" they must disclose the extent to which results claimed in studies "may be due to placebo effect or concomitant therapy."

An alleged violation of the $\mathrm{I}_{96}{ }_{3}$ fair-balance rules, involving some of the factors outlined above, led to the first seizure action under the advertising provisions of the 1962 amendments. On February 28, I966, U.S. marshals seized sixty-eight bottles containing I00 capsules each of Peritrate SA (pentaerythritol tetranitrate), sold by the Warner-Chilcott Laboratories Division of the Warner-Lambert Pharmaceutical $\mathrm{Co}^{93}{ }^{93}$ which did not contest the action. Peritrate has been widely used since 1952 to relieve the vise-like chest pain of angina pectoris, a coronary artery disease. Taken by millions of patients, the drug enlarges blood vessels narrowed by fatty deposits building up on their walls. But five-page journal ads ${ }^{24}$ suggested a new use for Peritrate-prolonging the life of heart patients by reducing the chance of subsequent attacks. Cited as support for this conclusion was one "long-range study of survival in 100 patients," in "well-matched treatment groups." Charts printed against a dramatic background of a sunset-lit ocean indicate that two years after myocardial infarction, 77.I per cent of the patients on Peritrate were still alive, in comparison with 44.7 per cent of those given a placebo, demonstrating "a significant trend toward

02 Washington Post, Nov. I4, 1966, at 3, col. I.

${ }_{03}^{03}$ The discussion of Peritrate seizure is based on Wall Street Journal, March I, 1966, at I, col. I; N.Y. Times, March I, I966, at 22, col. I; Medical Letrer, Jan. 28, 1966; Washington Post, March 4, I966, at 3 , col. $\mathbf{I}$.

o4 E.g., J.A.M.A., Dec. 6, x965, at 75-79. 
increased survival with Peritrate." On the last page of the ad a hand stretches toward the sun; superimposed on the full-color picture is the question: "Is Peritrate life-sustaining?"

The author of the cited study and the FDA answer that it is not. Dr. Alexander Oscharoff, chief of cardiology at Queens Hospital Center and Union Health Center in New York City, stated that he had never claimed "that Peritrate is the life-saving, dramatic drug that the advertising makes it." Dr. Oscharoff said that the ads were "distasteful," that he had "nothing to do" with them, and that after seeing them he had "objected" to the manufacturer. The FDA similarly charged that the Peritrate ads "falsely represented" Dr. Oscharoff's investigation. In addition, the Medical Letter has questioned the experiment itself, contesting the advertisement's claim that the two groups of patients were "well-matched."15 In fact, patients in the placebo group were older and more severely ill from the start than those on Peritrate, and therefore had dimmer chances of survival. The Letter concluded that "it seems unlikely that the FDA would accept a single ... study by a single investigator" as meaningful evidence for "one of the most intensive drug advertising campaigns of recent years ... [which] promotes a drug as a lifesaving agent in a serious disease."

The advertisement contains three references in addition to Dr. Oscharoff's study, which was published in a medical journal. Two were from inaccessible sourcesa paper presented by Dr. Oscharoff at the Ig64 annual meeting in Detroit, Michigan, of the Michigan Academy of General Practice, and "data on file" in the medical department of the manufacturer. The other reference supposedly supports a claim that Peritrate "stimulates development of collateral circulation." As the FDA charged, the ad does not disclose that this study was made on piglets "in a manner which in no way approximates the human disease situation." A second study by Dr. Oscharoff was not cited; this revealed that the number of deaths among Peritrate patients in the post-attack period was exactly the same as that among patients given a placebo. ${ }^{96}$ A spokesman for $J A M A$, however, said that the Peritrate ads "met our standards," which the Journal's advertising evaluation director has described as limiting "claims for useful products to those which can be documented by scientific fact."

In contrast, a recent three-page $\mathrm{ad}^{97}$ for Peritrate SA (billed as a "vignette of angina pectoris") claims merely that the drug has "been reported in clinical usage to reduce in number and severity the incidence of angina pectoris attacks," warning in the next paragraph of the promotional text that "the published literature contains both favorable and unfavorable clinical reports." The brief summary portion of the ad, which occupies two-thirds of a page, discusses the tests on pigs and adds that "these animal experiments cannot be translated to human behavior." However, the only

\footnotetext{
${ }^{95}$ Medical Letter, Jan. 28, ig66.

${ }^{90}$ Washington Post, March 4, r966, at 3, col. I.

or J.A.M.A., July 3I, I967, at 60-62.
} 
reference to this and other warning information on the two pages containing the promotional copy (but largely consisting of irrelevancies) is the direction in small print at the bottom of the second page, "See next page for full prescribing information."

In a speech to the New York City Pharamaceutical Advertising Club on October 20, $1966,{ }^{98}$ FDA general counsel William W. Goodrich criticized advertising for the eight new drugs introduced in 1965 which within a year ranked among the 200 most frequently prescribed drugs. Among the advertisements termed false or deceptive were the following:

Aventyl $\mathrm{HCl}$ (nortriptyline hydrochloride), Eli Lilly-Promotion uses "a new catch phrase to cover a host of 'target' symptoms, so that the drug is indicated and prescribed for the ordinary frustrations of daily living to reach a much larger patient population than the scientific data will support."

Indocin (indomethacin), Merck, Sharp \& Dohme-Ad claims greater longterm safety despite recent disclosure of new side effects; cites reference to support effectiveness claim without disclosing that the same study found "striking failures as well."

Lincocin (lincomycin hydrochloride monohydrate), Upjohn-Ad for antibiotic "obscures the most important information that the MD needs in using this drugthat hematologic toxicity can occur, and that the frequency of severe diarrhea is a unique feature of Lincocin therapy."

Tegopen (sodium cloxacillin monohydrate), Bristol_"The artwork, layout, and design of the ad" were meant "to impress the reader with the frequency with which Tegopen can be used, and not to carry the real message which the approval of the drug intended."

For the most part, the new regulations collect and codify advertising standards previously communicated to industry through letters, articles, and speeches by agency officials. By enumerating thirty or so specific practices as improper, the FDA hopes to overcome the genuine difficulties involved in translating the few words of the $x 962$ statute and the generalities of the 1963 regulations into decisions made on particular ads by the agency and by manufacturers (some of whom may not have adequate legal staffs). The industry withdrew its demands for a public hearing on the 1963 rules after then FDA Commissioner George P. Larrick sent two letters to industry counsel commenting on specific ads, although industry stated that it did not thereby concede that the FDA had broad regulatory powers over drug ad content. ${ }^{99}$ Following Dr. Goddard's appointment, agency officials have given a series of some ten speeches to industry and its advertising agencies calling attention to

\footnotetext{
${ }^{88}$ Address by FDA General Counsel Goodrich, supra note 9I, at S-10 to S-I2.

${ }^{\circ 0}$ Record at 131, 135, 137, In the Matter of Drugs: Prescription Drug Advertisements (Docket No. FDC-D-78), Prehearing Conference (Sept. 26, 1963).
} 
faults in drug ads and urging greater self-regulation. The new regulations should give more precise content to terms such as "fair balance."

Publicity attending the regulatory techniques used against defective ads has also disseminated the FDA's interpretation of the law. More recently, the agency has favored "dear doctor" letters from manufacturers to doctors to correct misleading ads. These warning letters fine the alleged offender the amount of their cost (about $\$ 40,000$ ), force a confession from him, and communicate the confession directly to those persons whom the ad may have misled. Also, the advertiser has in effect agreed to change all future promotion to match the correction. In contrast, either an injunction against the ad or seizure of the drug would come too late. A seizure action is effective from the FDA's point of view only if widely publicized. But the industry complains that unfavorable publicity flowing from seizures may result in sharp drops in sales because some doctors do not distinguish between defects in advertising and total lack of efficacy and safety of the drug itself. Of course, some danger exists that through the threat of seizure, injunction, criminal prosecution, and consequent publicity, the FDA may be able to force its views on industry on points that are reasonably debatable.

While it is true that FDA enforcement of its rules plus voluntary compliance by industry have effected great changes in the format and content of drug ads, this writer's survey of ads in recent journal issues indicates a wide divergence in understanding of the thrust of FDA policy. The separate, brief-summary portions of prescription drug ads do not always conform to a standard of "readability." The type size may be very small; ${ }^{100}$ headings such as "side effects" may not clearly stand out from the text; ${ }^{101}$ all the information may be lumped into one paragraph and not separated by white space; ${ }^{102}$ indications already presented in the ad body may be unnecessarily repeated; and warning data may be placed on the last page of a multipage spread where it can be overlooked. At the same time, many ads, especially one and two-page spreads, present the summary of limitations in readable type close to promotional claims. ${ }^{103}$ One ad varied this approach by stating in the promotional text, in the same type face and size: "Side effects, occurring in $9 \%$ of patients, seldom interfered with therapy. (For a description of side effects reported, see last page of this advertisement.)"104 As the extreme case, an ad for Indocin (indomethacin) presented four $\mathrm{X}$-ray pictures, one sentence on uses, and twenty-five sentences of warnings. ${ }^{105}$

In a number of journal ads, promotional claims in large type, colorful drawings

\footnotetext{
${ }^{100}$ E.g., Advertisement for Tepanil Ten-tab (diethylpropion hydrochloride), J.A.M.A., July 3x, I967, at 12.

${ }^{101}$ E.g., Advertisement for Dilantin (diphenylhydantoin), J.A.M.A., July 24, 1967, at $64-65$.

${ }^{102}$ E.g., Advertisement for Miltrate (meprobamate, pentaerythritol tetranitrate), J.A.M.A., July 24, I967, at 24-25.

${ }^{103}$ E.g., Advertisement for Kenalog (triamcinolone acetonide), J.A.M.A., Aug. 21, I967, at 46-47.

${ }^{104}$ Advertisement for Vontrol (diphenidol), NEw EnG. J. MED., July 6, 1967, at viii-x.

${ }^{105}$ Advertisement for Indocin (indomethacin), J.A.M.A., July 3I, 1967 , at 7 .
} 
and cartoons, and dramatic scenes portraying patients may overwhelm the cautionary information. A two-page ad for Hygroton (chlorthalidone), an oral diuretic, was composed of three horizontal strips running across facing pages. At the top was the promotional text ("to get rid of the fussiness, get rid of the puffiness"); underneath, and dominating the ad, a six-and-one-half-inch high picture of a woman's piercing eyes and nose; under the picture, the small print of the warnings (one-half inch high) was barely noticeable. ${ }^{106}$

Although the FDA states that its regulations require an adequate explanation of the limits of effectiveness, considerably different treatment is given to information supporting effectiveness and information restricting a drug's usefulness-the former appears in large type in the body of the ad, often with a citation, while the latter is conveyed to the doctor through a summary statement without reference as a side effect or contraindication, sometimes in an obscure part of the ad. Perhaps after the issuance of the ${ }^{1} 963$ rules there arose some legitimate confusion over the requirement that warning information must become "part of the central message of the advertisement." In two recent ads, statements that under certain conditions the drug must be used only as adjunctive therapy appeared in the promotional text of one $\mathrm{ad}^{107}$ but in the brief summary "indications" portion of the other. ${ }^{108}$

According to a study cited at the Kefauver hearings, ${ }^{109}$ doctors want less exaggerated and more informative ads, aimed at a higher level, accompanied by complete, clear research statistics, without cartoons or sensationalism. Many drug companies seem to have a low regard for the intellect of the average doctor. Consider, for example, a twelve-page ad placed in $J A M A^{110}$ in December 1965 by Warner-Chilcott (which manufactures Peritrate SA) for Tedral and Brondecon. The ad begins: "Like the Riders of the Apocalypse, to whom power was given to kill, there are abroad in the land Four Horsemen of the Alveoli." The first three of the pathologic "Horsemen" are identified as asthma, chronic bronchitis, and emphysema; the fourth, "the pale rider of therapeutic despair and diagnostic discouragement," is portrayed in a one-page color drawing as a naked man slumped wearily on a horse amidst dark clouds. In large type, the ad asks "What can be done?" and ominously warns doctors of impending influenza epidemics and air pollution-"There is cause for alarm." "Much can be done," of course, by prescribing Tedral, "the air that comes in tablets."

Advertisements for tranquilizers and sedatives are particularly offensive, and have more than likely contributed to the "astonishing expansion" in the use of such drugs

\footnotetext{
${ }^{100}$ J.A.M.A., July 24,1967 , at 20-21.

${ }^{107}$ Advertisement for Depo-Medrol (methylprednisolone acetate), J.A.M.A., July 24, 1967, at 32-33. The ad text reads in part: "In such chronic diseases as arthritis, Medrol should be regarded as adjunctive therapy and not as replacement for standard measures."

${ }^{103}$ Advertisement for Miltown (meprobamate), J.A.M.A., Aug. 21, 1967, at 218-19. The ad's brief summary portion reads in part: "Indications: Effective in relief of anxiety and tension states; adjunctively when anxiety may be causative or disturbing factor."

${ }^{108}$ S. REP. No. 448 , at $\times 63-64$.

${ }^{120}$ J.A.M.A., Dec. 6, 1965, at II-22.
} 
and their "phenomenal abuse" by doctors within the past several years. ${ }^{111}$ Vividly illustrated, these ads suggest that tranquilizers supply the answer to almost all social problems-for the elderly woman "in senile agitation" clutching her dog, worried because her pension check is late; for the husband yelling at his wife over a bill; for the young woman crawling into bed with her teddy bear, nudged to sleep by a drug; for the man who has lost his wife, job, or self-esteem; and for the unhappy person experiencing "the fluctuating symptoms of Behavioral Drift." ("I keep pacing back and forth. I think I'm going to pieces.") An ad promotes Miltown (meprobamate) as helping to "control the underlying problem-anxiety- ... when reassurance is not enough," 112 an open-ended claim that sweeps broadly to catch a large proportion of today's urban population who need more than reassurance, although not necessarily Miltown. It is not surprising, therefore, that tranquilizers are being used less as a medication than as agents for producing sleep, a sense of happiness, and relaxation. ${ }^{113}$ Although the FDA could not order that advertisements be more dignified, enforcement of the fair balance regulations plus general pressure toward scientific presentation of drug claims might incidentally result in ads aimed at a higher scientific level.

\section{$\mathrm{V}$}

\section{Future Developments}

The Kefauver Drug Amendments of 1962, and regulations issued by the Food and Drug Administration to implement them, have produced significant and desirable changes in prescription drug promotion. At the minimum, drug maufacturers have complied with rules that are relatively unambiguous-that is, where noncompliance would be conspicuous. Thus drug ads today at least list the side effects associated with the promoted drug. And although it may be impossible to estimate to what extent lack of full disclosure or unsubstantiated claims made in pre-1962 drug literature caused misuse of drugs with consequent adverse effects, the new law provides some safeguards against such occurrences. ${ }^{114}$

Promotion for prescription drugs differs significantly from that for ordinary consumer goods. Ads for consumer goods may stimulate aggregate demand for an industry's product in addition to shifting demand among fungible brands of goods (such as perfumes) which are quasi-useful and which lack any real potential for good or harm. But no color photograph of a sunset ${ }^{115}$ will ever create greater demand for medication to treat one class of diseases (such as epilepsy). In fact, it is the constant need for genuine medical progress, for the discovery and immediate use of drugs with proven greater effectiveness and safety, that justifies regulatory control.

\footnotetext{
${ }^{111}$ N.Y. Times, March $1_{3}, 1966$, at 32 , col. 3 (city ed.).

112 J.A.M.A., Aug. 21, I967, at 218-I9.

118 N.Y. Times, March I3, 1966 , at 32, col. 3 (city ed.).

114 Pisani, supra note 68 , at 75 .

${ }^{115}$ Advertisement for Dilantin, supra note ror.
} 
When such drugs are marketed, the "art of persuasion" and exaggerated claimsor the failure to stress the unique limitation of a new drug among others used to treat the same illness-must not lull doctors looking to ads for information into easy acceptance either of inferior drugs or of equally effective drugs which may be inappropriate for a particular patient.

While physicians may be no more "immune to the contemporary scene" than other persons, it does not follow that one cannot, "in a world dominated by singing commercials and neon lights ... . expect to attract attention to any message if you clothe it in dull, eighteenth-century garb."116 Doctors are not the ultimate consumers of drugs; they are agents entrusted to exercise dispassionate scientific judgment on scientific questions. ${ }^{117}$ Communications phrased more like letters than billboards, with relevant illustrations, are just as likely to catch the attention of a doctor treating a patient for a painful, crippling disease as are more flamboyant, enthusiastic, and colorful reviews. And if it is true that misleading advertising destroys doctors' confidence in the pharmaceutical industry, ${ }^{118}$ manufacturers should not hesitate to rely on facts to sell drugs, "facts presented in a professional way for professional men to read with care and respect."119

Dr. James L. Goddard, FDA Commissioner, has asked physicians to assist the agency to review drug effectiveness and eliminate abuses in clinical testing of new drugs. The medical profession could also take a more responsible stand in helping the FDA monitor drug advertising by reporting adverse reactions not adequately revealed in the brief summary; by expressing to detailers and manufacturers their distaste for overpromotion; and by using publications such as the Medical Letter to obtain more balanced pictures of drugs. Medical schools should take the initiative in teaching doctors how to evaluate promotional literature and how to supplement it with drug data from other sources.

Future relations between the FDA and industry will continue to include minor skirmishing, with industry contesting some FDA regulatory actions against drug promotion but acquiescing in others. The industry may contest the new advertising regulations in court, having forced the FDA to retreat on the every-time requirement. Recently drug companies have voluntarily submitted many ads for new drugs, which the FDA watches carefully, for advance clearance by the agency. (The statute bars the FDA from requiring advance approval except in "extraordinary circumstances." ${ }^{120}$ ) The industry has complained that the agency has been arbitrary in its choice of ads to criticize and its choice of regulatory techniques to employ in individual cases.

\footnotetext{
${ }^{310}$ Jurow, supra note 4 , at 62,63 .

117 The fact that doctors act as purchasing agents for their patients minimizes the influences of prices on the volume of prescription drug sales. Steele, stupra note I4, at 132.

${ }^{118}$ S. REP. No. 448 , at 155 .

${ }^{110}$ Address by FDA Commissioner Goddard, supra note 5 .

${ }^{120} 21$ U.S.C. $\$ 352$ (n) (I964).
} 
Ironically, just as the conflict over drug advertising intensifies, the importance of medical journal advertising may be on the decline for a variety of reasons, which the following paragraphs suggest.

First, companies may direct their promotional efforts more at hospitals and government agencies and less at individual doctors reached through journals. Here the detailers, over whose oral statements the FDA exercises little control, may play a larger role. But large institutions cannot be misled or overawed as easily as can the single practitioner; in addition, hospitals have programs for monitoring drug reactions and effectiveness. In reviewing new drug labeling, the FDA has recently been carefully examining the material prepared for the detailer to leave with doctors during sales talks. And as more doctors become associated with hospitals or medical centers, more will learn of the effectiveness and limitations of new drugs through hospital and clinic committees.

Second, government agencies buying drugs under Medicare, Medicaid, and other programs may limit buying to little-advertised generic name drugs. The sheer volume of advertising for trade name drugs may obscure the existence of these generic drugs from the general practitioner. ${ }^{121}$

Third, each year the number of new drugs, the most heavily advertised, decreases. Thus, while forty-five new chemical entities were introduced in rg6o, only thirteen were introduced in 1966 . Reasons for this decline may include the FDA's tightening of rules on advertising content, which has diminished the manufacturers' ability to differentiate their trade-name products. But more stringent FDA policies with regard to testing and approving new drugs may have played a greater role in the reduction in the flow of new drug products. ${ }^{122}$

Fourth, techniques such as films and company-sponsored seminars may be stressed to a greater extent. Today detailers may show films on drug use at medical conventions and hospital meetings. Promotional films for one drug, or for a class of drugs one of which is marketed by a sponsoring company, when used in a promotional setting, are classified as labeling. In a concession to industry, the proposed regulations require only that such films spell out the drug's "major" side effects, provided they mention that full-disclosure information will be distributed to the audience.

Fifth, publication of a government-approved manual on drugs, reproducing fulldisclosure labeling and updated with frequent supplements, may eventually replace advertisements as a major source of drug information for doctors. As yet, however, the industry has not agreed to subsidize such a publication, which would list drugs by generic name.

\footnotetext{
121 Steele, supra note I4, at I47. According to William S. Comanor, assistant professor of economics at Harvard University, the volume of advertising for a particular drug may in some cases be more important than the ad content in inducing prescriptions from doctors who are uncertain about the relative merits of competing products. Washington Post, Jan. 26, 1968, at 6, col. I (capital ed.).

${ }^{122}$ N.Y. Times, June $4,1967, \S 3$, at $x$, col. 2.
} 
During the next several years industry and government, either in a spirit of cooperation or in a mood of mutual and militant hostility, will determine the extent of legal control over the advertising of prescription drugs. The final result will be of great significance, for "except only those great decisions that lead to peace or war, it is difficult to think of any that affect so many lives for so long to come or affect them in such important ways."123

${ }^{123}$ Address by Alanson W. Willcox, General Counsel, Department of Health, Education, and Welfare, Charles Wesley Dunn Lecture at Harvard Law School, March 15, I963. 